\begin{tabular}{|c|c|c|}
\hline 8 PrOLOG/C & http://dergipark.gov.tr/anatolianbryology & $\begin{array}{c}\text { Anatolian Bryology } \\
\text { Anadolu Briyoloji Dergisi } \\
\text { Review Article }\end{array}$ \\
\hline 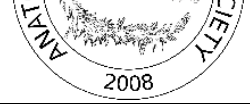 & DOI: $10.26672 /$ anatolianbryology.350332 & $\begin{array}{l}\text { ISSN:2149-5920 Print } \\
\text { e-ISSN:2458-8474 Online }\end{array}$ \\
\hline
\end{tabular}

Türkiye'deki Milli Parkların Briyofit Zenginliği Açısından İrdelenmesi

\author{
*Satı SARIOĞLU1 ${ }^{1}$, Zeki IŞIN ${ }^{2}$, Serhat URSAVAŞ ${ }^{3}$, Tamer KEÇELI ${ }^{4}$ \\ ${ }^{I}$ Çankirl Karatekin University, Graduate School of Natural and Applied Science, Department of Biology \\ ${ }^{2}$ Çankirl Karatekin University, Graduate School of Natural and Applied Science, Department of Forest \\ Engineering \\ ${ }^{3}$ Çankirl Karatekin University, Faculty of Forestry, Department of Forest Engineering \\ ${ }^{4}$ Çankirl Karatekin University, Faculty of Science, Department of Biology
}

\begin{abstract}
Received: 09.11.2017
Revised: 22.11.2017

Accepted: 24.11.2017

Öz

Milli Parklar, bilimsel ve estetik açıdan milli ve milletlerarası ender bulunan doğal ve kültürel kaynak değerler ile koruma, dinlenme ve turizm alanlarına sahip olan ve yönetimi belli yasalar çerçevesinde gerçekleştirilen tabiat parçalarıdır. Yakın zamanda, gelecek nesillere çağımızın beton kalıntılarını değil, insanlar tarafından bozulmamış, doğal çevreyi ve içerisindeki kaynak değerleri de bırakma düşüncesi hakim olmuştur. Bu açıdan, Ulusal ve Uluslararası düzeyde doğal ve kültürel tabiat parçaları olarak tanımladığımız Milli Park uygulamalarına başlanmıştır.
\end{abstract}

Türkiye'nin ilk Milli Parkı 1958 yılında ilan edilen Yozgat Çamlığı'dır. Türkiye'de şimdiye kadar toplam da 43 adet Milli Park ilan edilmiş olup, bunlardan 1 tanesinin Milli Park statüsü sonradan kaldırılmıştır. Mevcut olan 42 adet Milli Park'ın toplam alanı ise 851.378,85 ha.'dır.

Şimdiye kadar, Türkiye'deki 42 adet Milli Park'ın 16 tanesinde briyofit flora çalışması gerçekleştirilmiştir. Yapılan bu briyofit flora çalışmaları sonucunda; 2 endemik, 29 yeni kayıt, 15 ikinci kayıt ve 489 yeni kare kaydı verilmiştir.

Anahtar kelimeler: Milli Park, Briyofit, Endemik, Yeni kayıt, Türkiye

\title{
Evaluation of Bryophyte Diversity in National Parks of Turkey
}

\begin{abstract}
National Parks are aesthetically and scientifically important natural areas which are valued for their rare national and international natural and cultural resource values and contain conservation, recreation and tourism areas and whose management is carried out under certain laws. In the near future, the idea of leaving the natural environment and resources that are not damaged by people instead of our ancient concrete remains to future generations have been dominated. From this point of view, establishment of national parks that we have defined as natural and cultural nature fragments at national and international level have begun.
\end{abstract}

Turkey's first National Park is the Yozgat Çamlığı which was declared in 1958. In Turkey, 43 national parks have been declared up to now, and the status of one of them has been abolished afterwards. The total area of 42 existing National Parks is $851.378,85$ ha.

Up to now, 16 Bryophyte flora studies have been carried out from 42 National Parks in Turkey. 2 endemic, 29 new records, 15 second records and 489 new square record were recorded for Turkey in these Bryophyte studies.

Key words: National Park, Bryophyte, Endemic, New record, Turkey

* Corresponding author: satisarioglu@ hotmail.com

(C) 2017 All rights reserved / Tüm haklarl saklıdır.

To cite this article: Sarıŏlu S. Işın Z. Ursavaş S. Keçeli T. 2017. Evaluation of Bryophyte Diversity in National

Parks of Turkey. Anatolian Bryology. 3(2): 103-115. 


\section{Giriş}

Türkiye'nin korunan alanlar sistemi içinde yer alan mevcut korunan alanlar; estetik, bilim, doğa koruma ve doğal güzellikler açısından sınırları belirlenmiş önemli alanları içermektedir. Türkiye'nin korunan alanları; deniz ve kıyılardan Ağrı Dağı'na, deltalardan Karadeniz ormanlarına ve yaylalarına, bozkırlardan göl ve akarsu sistemlerine, derin vadiler ve kanyonlardan buzullara kadar çeşitli doğal ekosistemleri barındırır. Korunan alanlar; nesli tehlike altında, endemik, dar yayılımlı birçok bitki ve hayvan türüne ev sahipliği yapmaktadır. Ayrıca, ekolojik özellikleri ve doğal güzelliklerin yanı sıra jeolojik, jeomorfolojik, peyzaj, tarihi, arkeolojik ve kültürel değerlere sahip alanları da içermektedir. Türkiye'nin karasal alanlarının \% 7,24'ü resmi koruma altındadır. Korunan alanların; ekonomik, ekolojik, kültürel ve sosyal birçok faydası bulunmaktadır (OGM, 2017).

$\mathrm{Bu}$ çalışmanın amacı, ülkemizin korunan alanlarından olan milli parklarımızda yapılmış olan briyofit çalışmalarını derlemek, yapılan çalışmalar neticesinde hangi milli parklarımızda ne kadar karayosunu ve ciğerotu kaydının verildiği, verilen kayıtlar içerisinde önemli yeni kayıt veya yeni kare kayıtlarının listesini vererek durum değerlendirmesi yapmaktır. Aynı zamanda, şimdiye kadar briyofit florası bakımından herhangi bir çalışma yapılmamış olan milli parklarımızı belirleyerek bu alanların bir an önce briyofit florasının çıkartılması yönünde bir farkındalık yaratmak amaçlanmıştır.

\section{Materyal Metot}

Türkiye'de mevcut olan 42 adet Milli Parkımızda şimdiye kadar gerçekleştirilmiş olan briyofit flora çalışmaları incelenmiştir. Yapılmış olan bu çalışmalardaki karayosunu ve ciğerotu sayıları familya, cins ve tür düzeyinde verilmiştir. Alandan tespit edilen türler içerisinde o zaman için Türkiye'den ilk defa kaydı verilen taksonların başına üçgen $(\boldsymbol{\Delta})$ işareti, Türkiye'den ikinci defa kaydı verilen taksonların başına kare (घ) işareti ve bilim dünyasına yeni kazandırılmış olan taksonların başına ise (C) simgesi ile belirtilmiştir. Henderson (1961) kareleme sistemine göre yer aldığı kareden ilk defa kaydı verilen taksonların sadece sayıları verilmiştir (Şekil 1).

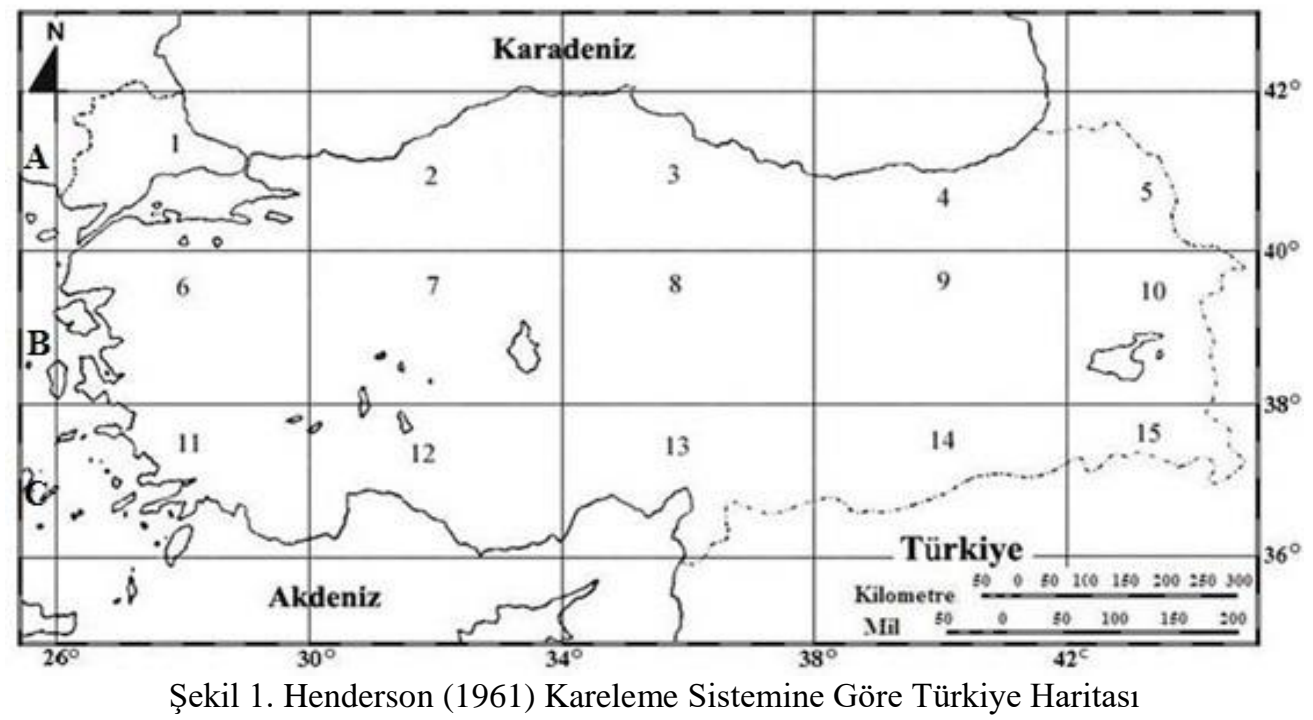

\section{Türkiye'nin Milli Parkları}

Ülkemizin ilk Milli Parkı, 1958 yılında ilan edilen Yozgat Çamlığı Milli Parkı'dır. Ülkemizde şimdiye kadar toplam 43 adet Milli Park ilan edilmiş olup, bunlardan 1 tanesinin (Gelibolu Yarımadası ve Tarihi Milli Parkı: 2014'te) Milli Park statüsü kaldırılmıştır. Mevcut olan 42 adet Milli Park toplam alanı 851.378,85 ha.'dır (OGM, 2017).

\section{1. Ă̆rı Dağı Milli Parkı}

Doğu Anadolu Bölgesi'nin Ağrı İli sınırları içinde yer almaktadır. 2004 yılında ilan edilmiş olan Milli Parkın yüz ölçümü 88.014 hektardır. Ağrı Dağı $5.137 \mathrm{~m}$. rakımı ile Türkiye'nin en yüksek dağ olma unvanını taşımaktadır (URL 1). Alanda briyofit florasına yönelik şimdiye kadar herhangi bir çalışma yapılmamıştır.

\subsection{Aladağlar Milli Parkı}

Akdeniz Bölgesi'nin, Niğde, Kayseri, Adana illeri sınırları içinde yer almaktadır. 1995 yılında ilan edilmiş olan Milli Parkımızın yüz ölçümü 55.064 hektardır. Toros sıradağlarının en yüksek zirvelerine sahip olan Aladağlar jeolojik olarak da ülkemizin en ilginç yerlerinden biridir (URL 2). Özlem Tonguç Yayıntaş (2009) tarafindan Aladağlar Milli Parkında (1700 m), $\mathbf{\Delta}$ Trachycystis ussuriensis'in toprak üzerinden kaydı verilmiştir. 
Ezer ve ark. (2015) tarafından yapılmış olan "The Bryophyte Flora of Aladağlar National Park (Turkey)" adlı çalışma sonunda alandan; 29 familya ve 75 cinse ait 236 karayosunu taksonu kaydı verilmiştir. Bunlardan; 口Physcomitrium

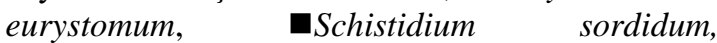
-Brachythecium capillaceum ve $\mathbf{0 y p n u m}$ bambergeri'nin Türkiye'den ikinci kez kaydı verilmiştir. Ayrıca, 8 familya ve 9 cinse ait 13 ciğerotu taksonunun kaydı verilmiştir. $\mathrm{Bu}$ taksonlardan; Marchantia polymorpha ve -Preissia quadrata Türkiye'den ikinci kez kaydı verilen taksonlardır. Toplamda ise; 57 karayosunu ve 3 ciğerotu taksonu Henderson (1961) kareleme sistemine göre C13 karesi için yeni kayıttır.

\subsection{Altınbeşik Mağarası Milli Parkı}

Akdeniz Bölgesi'nin Antalya ili sınırları içinde yer almaktadır. Orta Torosların karstik yapısı içinde üç katlı bir mağara sistemidir. Üst katında sarkıt ve dikitler bulunmaktadır. Mağaranın girişinden itibaren ilk 200 metre mağaranın alt seviyesini oluşturur ve burası devamlı su altındadır. Bununla birlikte mağaranın alt ve orta seviyelerde ise bir yeraltı akarsuyu vardır. Bu yer altı suyu kurak mevsim olan güz mevsiminde mağaraya girildiğinde anlaşılmaktadır (URL 3). Mağaranın toplam uzunluğu $2.500 \mathrm{~m}$ olup, girişe göre en yüksek noktası 101 m'dir (URL 4). Alanda briyofit florasına yönelik herhangi bir çalışma yapılmamıştır.

\subsection{Altındere Vadisi Milli Parkı}

Doğu Karadeniz Bölgesi’nin Trabzon ili sınırları içinde yer alır. Alan 1987 yılında Milli Park ilan edilmiştir ve yüz ölçümü 4.468 hektardır. Sümela Manastırı, Altındere Vadisi ve bu vadinin jeomorfolojik yapısı ile flora ve faunası Milli Parkın kaynak değerini oluşturmaktadır (URL 5).

Baydar ve Özdemir (1996) tarafindan yapılan çalışmaya göre; 15 familya ve 31 cinse ait 40 karayosunu taksonu kaydı verilmiştir. $\mathrm{Bu}$ taksonlardan 4 tanesi Herderson (1961) kareleme sistemine göre A4 karesi için yeni kayıttır.

Ayrıca; 2008 yılı ayında yapılan bir başka araştırmada ise milli parktaki karayosunları üzerinde yetişen alg popülasyonu araştırılmış ve 15 tane Bacillariophyta, 7 tane Cyanophyta, 4 tane Chlorophyta ve 1 adet de Euglenophyta taksonu bulunmuştur. $\mathrm{Bu}$ taksonlar arasında bulunan Netrium digitus var. curtum Türünün Türkiye florası için yeni kayıt olduğu ifade edilmiştir (Şahin ve Özdemir, 2008).

Gökler (1998) tarafindan yapılmış olan "Altındere Vadisi Milli Parkı Ciğerotları (Marchantiopsida)" adlı çalışma sonucunda alandan; 16 familyaya ve
18 cinse ait 33 ciğerotu taksonunun kaydı verilmiştir. Bu taksonlardan 4 tanesi A4 karesi için yeni kayıtır.

\subsection{Başkomutan Tarihi Milli Parkı}

İç Batı Anadolu'nun Afyon, Kütahya, Uşak illeri sınırları içindedir. 1981 yılında ilan edilmiş ve yüz ölçümü 40.948 hektardır. Türk Kurtuluş Savaşında 26 Ağustos 1922'de başlayan Büyük Taarruz' un 30 Ağustosta zaferle taçlandırılmasıyla sonuçlanan harekâtın geçtiği alanları kapsayan Milli Parkta, Kurtuluş Savaşımıza ait tarihi yerler, anıtlar ve şehitlikler bulunmaktadır. Milli Park özellikle otsu florasıyla ilgi çekmekte olup, içerisinde birçok endemik taksonu barındırmaktadır (URL 6). Milli Parkta briyofit florasına yönelik herhangi bir çalışma yapılmamıştır.

\subsection{Beydağları Sahil Milli Parkı}

Milli Park, Akdeniz Bölgesinin Antalya ili sınırları içinde yer almaktadır. 1972 yılında ilan edilmiş ve yüz ölçümü 31.018 hektardır. Zengin biyolojik çeşitlilik, epik ve jeomorfolojik oluşum ile birlikte, 1972 yılında, 69.800 hektarlık alan Milli Park alanı olarak ilan edilmiş. 1988 yılında yerleşim alanlarının Milli Park sınırları dışında bırakılması ile park bugün 34.425 hektarlık bir alana sahiptir (URL 7). Alanda briyofit florasina yönelik herhangi bir çalışma yapılmamıştır.

\subsection{Beyșehir Gölü Milli Parkı}

İç Anadolu Bölgesi'nin Konya ili sınırları içerisinde yer almaktadır. 1993 yılında ilan edilmiş ve yüz ölçümü 86.855 hektardır. Beyşehir Gölü, yüz ölçümü bakımından Van ve Tuz Gölünden sonra üçüncü büyük gölümüz olmakla birlikte, tatlı su göllerimiz içinde en büyük olanıdır (URL 8). Alanda briyofit florasına yönelik herhangi bir çalışma yapılmamıştır.

\subsection{Boğazköy-Alacahöyük Milli Parkı}

İç Anadolu Bölgesi’nin Çorum ili sınırları içindedir. 1988 yılında ilan edilmiş ve yüz ölçümü 2.600 hektardır. Milli Parkta Anadolu'nun en eski uygarlıklarından olan Hitit'lere başkentlik yapmış Hattuşaş (Boğazköy) ve çevresindeki çeşitli tarihi eserler bulunmaktadır (URL 9). Alanda briyofit florasına yönelik herhangi bir çalışma yapılmamıştır.

\subsection{Dilek Yarımadası-Büyük Menderes Deltası Milli Parkı}

Milli Park Ege Bölgesinin Aydın ili sınırlarında yer alır. Dilek Yarımadası 1966 yılında, Büyük Menderes Deltası ise 1994 yılında ilan edilmiştir. 10.985 hektarı yarımada, 16.613 hektarı delta olmak üzere toplam 27.598 hektarlık bir yüz ölçümüne sahiptir (URL 10). 
Çetin (1988a) tarafından yapılan çalışmaya göre; 11 familya ve 22 cinse ait 29 karayosunu taksonu tespit edilmiştir. Tespit edilen önemli taksonlar şunlardır; $\mathbf{\Delta}$ Fissidens adianthoides ve $\Delta$ Encalypta rhabdocarpa var. leptodon. $\mathrm{Bu}$ taksonlardan 2 tanesi ise C11 karesi için yeni kayıtır.

Özenoğlu ve Gökler (2002) tarafindan gerçekleştirilen "Dilek Yarımadası Milli Parkı Ciğerotları (Marchantiopsida)" adlı çalışmada; 18 familyaya ait 18 cins ve 26 takson tespit edilmiştir. $\mathrm{Bu}$ taksonlardan 6 tanesi $\mathrm{C} 11$ karesi için yeni kayıttır. Ayrıca bu alandan; Gökler ve ark. (2000) tarafından Türkiye için yeni bir kayıt olan $\Delta$ Riccia crozalsii Türkiye briyofit florasına eklenmiştir.

\subsection{Gala Gölü Milli Parkı}

Marmara Bölgesi'nin Edirne ili, Enez ve İpsala ilçesi sınırları içerisinde yer alan Pamuklu ve Küçük Gala Göllerini kapsayan 2.369 hektarlık alan 1991 tarihinde Bakanlar Kurulu Kararı ile Tabiatı Koruma Alanı olarak ilan edilmiş olup, 2873 sayılı Milli Parklar Kanunu'nun 3. maddesi gereğince 2005 yılında Bakanlar Kurulu kararı ile sınırları genişletilerek (6.087 hektar) Milli Park olarak ilan edilmiştir (URL 11). Alanda briyofit florasına yönelik herhangi bir çalışma yapılmamıştır.

\subsection{Göreme Tarihi Milli Parkı}

İç Anadolu Bölgesi'nin Nevşehir ili sınırları içinde yer almaktadır. 1986 yılında ilan edilmiş ve yüzölçümü 9.614 hektardır (URL 12). Birleşmiş Milletler Eğitim - Bilim ve Kültür Teşkilatı (UNESCO) tarafindan 6.12.1985 tarihinde 357. sirada "Göreme Tarihi Milli Parkı ve Kapadokya'nın Kayalık Alanları” adıyla Dünya Doğal ve Kültürel Mirası Listesine alınmış olup ülkemizde bu listede bulunan 9 Yerden birisi durumundadır (URL13). Alanda briyofit florasına yönelik herhangi bir çalışma yapılmamıştır.

\subsection{Hatila Vadisi Milli Parkı}

Doğu Karadeniz Bölgesi'nin Artvin ili sınırları içinde yer almaktadır. 1994 yılında ilan edilmiş ve yüz ölçümü 16.944 hektardır (URL 14).

Batan ve Özdemir (2008) tarafindan gerçekleştirilen çalışmada; 16 familya ve 44 cinse ait 85 takson tespit edilmiştir. Bu taksonlardan;

A Didymodon asperifolius, toprak üzerinden (1300 m) tespit edilmiştir. Özdemir ve ark., (2008) tarafından gerçekleştirilen çalışmada ise $\Delta$ Grimmia ramondii dere kenarı kaya üzerinden $(1300 \mathrm{~m})$ tespit edilmiştir. Bu taksonlardan 6 tanesi A4 karesi için yeni kayıttır.

\subsection{Honaz Dağı Milli Parkı}

Ege Bölgesi'nin Denizli ili sınırları içinde yer almaktadır. Alandaki Milli Park 1995 yılında ilan edilmiş ve 1998'de alanın sınırlarında değişikliği yapılmıştır. Yüz ölçümü 9.429 hektardır. 2.528 metrelik zirvesi ile Ege Bölgesinin en yüksek noktası olan Honaz Dağı jeolojik yapısında periglasiyel formasyonlar göstermektedir (URL 15).

Alanda briyofit florasına ait Kırmacı ve Erdağ (2009) tarafından gerçekleştirilen çalışmada; 24 familya ve 64 cinse ait 175 karayosunu taksonu tespit edilmiş olup önemli taksonlar şunlardır: $\boldsymbol{\Delta}$ Orthotrichum rivulare ve $\boldsymbol{\Delta}$ Weissia breutelii. Ciğerotlarından; 14 familya ve 16 cinse ait 20 takson ve boynuzotlarından ise 1 takson tespit edilmiştir.

\subsection{4. İğneada Longoz Ormanları Milli Parkı}

3.155 hektarlık Milli Park alanı, İğneada Beldesi sınırları içerisinde yer almaktadır. İğneada, Marmara Bölgesi, Kırklareli İli Demirköy İlçesine bağlı, Bulgaristan ile sınırı olan bir sahil kasabasıdır. Demirköy’e 25 km uzaklıktadır (URL 16). Alanda briyofit florasına yönelik bir çalışma yürütülmektedir.

\subsection{Ilgaz Dağı Milli Parkı}

Batı Karadeniz Bölgesi'nin, Çankırı ve Kastamonu illeri sınırları içinde yer almaktadır. 1976 yılında ilan edilmiş ve yüz ölçümü 1.118 hektardır (URL 17). Ilgaz Dağı Milli Park alanının tamamı 1997 yılında ilan edilen Kastamonu-Çankırı Ilgaz Kış Sporları Turizm Merkezi içerisinde kalmaktadır. Karadeniz ve İç Anadolu Bölgeleri arasındaki geçiş kuşağında yer alması, Ilgaz Dağlarının zengin bir tür ve habitat çeşitliliğine sahip olmasını sağlamıştır (URL 18).

Abay ve Çetin (2003) tarafından gerçekleştirilen çalışma sonucunda; 21 familya ve 56 cinse ait 109 takson tespit edilmiş olup bunlardan 15 takson A2 karesi için yeni kayıttır.

Şimşek ve ark., (2011) tarafindan gerçekleştirilen "Ilgaz Dağları (Türkiye) Ciğerotları (Marchantiophyta) Florasına Katkılar" adlı çalışmada; 15 familyaya ait 19 cins ve 24 ciğerotu taksonu tespit edilmiştir. Bu taksonlardan 2 tanesi A2 karesi için yeni kayıttır.

\subsection{Kaçkar Dağları Milli Parkı}

Milli Park Doğu Karadeniz Bölgesi’nin Rize ili sınırları içindedir. 1994 yılında ilan edilmiş ve yüz ölçümü 52.970 hektardır. Dört bin metreye yaklaşan zirvesi ile Karadeniz bölgesinin en yüksek dağlarıdır (URL 19). 
Kırmacı (2009) tarafından gerçekleştirilen çalışmada; $\Delta$ Schistidium dupretii'nin Kaçkar Dağları Milli Parkında (1050 m) kaya üzerinden kaydı verilmiştir.

Abay ve ark., (2007) tarafindan gerçekleştirilen çalışmada; $\quad \mathbf{\Delta}$ Bucklandiella microcarpa'nın Kaçkar Dağları Milli Parkında (2680 m), kaya üzerinden kaydı verilmiştir.

Uyar ve ark., (2008) tarafından gerçekleştirilen çalışmada; $\Delta$ Dicranum flexicaule'nin Avsor yaylasında $(2360 \mathrm{~m})$, toprak üzerinden kaydı verilmiştir.

Abay ve ark., (2009a) tarafindan yapilan "Sphagnum centrale and other remarkable bryophyte records from the Kaçkar Mountains (Northern Turkey)" adlı çalışmada; 58 familya ve 125 cinse ait 255 karayosunu taksonu tespit edilmiştir. Bu taksonlardan 8 tanesi A4 karesi için yeni kayıttır. Ayrıca; $\Delta$ Sphagnum centrale Avsor yaylasında $(2300 \mathrm{~m})$, 1slak toprak üzerinden kaydı verilen karayosunu taksonudur.

Abay ve ark (2009b) tarafindan yapilan "New Bryofloristic records for the square A4 (Rize Turkey)" adlı çalışma sonucunda; 18 familya ve 32 cinse ait 38 ciğerotu taksonu kaydedilmiştir. Bu taksonlardan önemli olan aedinophyllum interruptum'dur. Ayrıca 5 takson A4 karesi için yeni kayıttır.

\subsection{Karagöl-Sahara Milli Parkı}

Doğu Karadeniz Bölgesi'nin Artvin ili sınırları içinde yer almaktadır. 1994 yılında ilan edilmiştir. Yüz ölçümü 3.251 hektardır (URL 20). Alanda briyofit florasına yönelik herhangi bir çalışma yapılmamıştır.

\subsection{Karatepe-Aslantaş Milli Parkı}

Akdeniz Bölgesi'nin Osmaniye ili sınırları içindedir. 1958 yılında ilan edilmiş olup yüz ölçümü 4.145 hektardır. Geç Hitit döneminin (M.Ö. 8. Yüzyıl) önemli yerleşimlerinin ve kalesinin bulunduğu bir alandır. Roma ve Bizans dönemlerinde de yerleşmeler olmuştur. Milli parkta bu dönemlere ait eserler bulunmaktadır (URL 21). Alanda briyofit florasına yönelik herhangi bir çalışma yapılmamıştır.

\subsection{Kazdağı Milli Parkı}

Marmara ve Ege Bölgeleri arasında geçiş bölgesinin Balıkesir ili sınırları içinde yer alır. 1994 y1lında Milli Park ilan edilmiș olup yüz ölçümü 20.935 hektardır. Antik çağlarda İda dağı olarak bilinen Kaz Dağı, Biga Yarımadasının en yüksek dağıdır (URL 22).
Erdağ ve Yayıntaş (1996) tarafindan gerçekleştirilen çalışma sonucunda: 23 familya ve 63 cinse ait 139 karayosunu takson tespit edilmiş olup bunlardan; $\boldsymbol{\Delta}$ Brachythecium latifolium Türkiye için ilk kez rapor edilmiştir. Ayrıca, alandan tespit edilen taksonlardan 12 tanesi B6 karesi için yeni kayıttır.

Gökler ve Özenoğlu (1999) tarafindan gerçekleştirilen "Kazdağı Milli Parkı ve Çevresi Ciğer Otlarının Taksonomisi ve Ekolojisi" adlı çalışma sonunda; 12 Familya ve 17 cinse ait 22 ciğerotu taksonun tespit edilmiştir. Bunlardan 5 tanesi B6 karesi için yeni kayıttır.

Keçeli (2015) tarafından yapılmış olan "Ayazma Tabiat Parkı (Çanakkale), Kaz Dağları Milli Parkı (Balıkesir) Ciğerotu Florasına Katkılar" adlı çalışma sonunda; 15 familya ve 15 cinse ait 22 takson belirlenmiştir.

\subsection{Kızıldağ Milli Parkı}

Akdeniz Bölgesi'nin Isparta ili sınırları içindedir. 1969 yılında Milli Park ilan edilmiş olup yüz ölçümü 55.106 hektardır. Jeolojik olarak karstik bir yapıya sahip olan milli parkta, ünlü Pınar Gözü Mağarası bulunmaktadır (URL 23)

Ursavaş ve Çetin (2013) tarafından gerçekleştirilen çalışma sonucunda; 29 familya ve 66 cinse ait 156 karayosunu taksonu tespit edilmiştir. $\mathrm{Bu}$ taksonlardan; Türkiye için yeni kayıt olan,

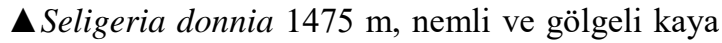
üzerinden tespit edilmiştir (Ursavaş ve Çetin, 2012). Ayrıca dünya literatürüne ilk kez kayıt edilen ve ülkemiz için endemik olan (C) Cinclidotus asumaniae türü de bu araştırma sonucunda tespit edilmiştir (Ursavaş and Çetin, 2014). Yine bu çalışma ile ülkemiz için endemik olan bir başka Cindidotus taksonu olan $\mathbf{m}$. vardaranus için yeni bir yayılış alanı tespit edilmiştir. Ayrıca, 7 takson B7 karesi için, 47 takson C12 karesi için ve 9 takson ise her iki kare (B7-C12) için yeni kayıttır.

\subsection{Kovada Gölü Milli Parkı}

Akdeniz Bölgesi'nin Isparta ili sınırları içindedir. 1970 yılında ilan edilmiş olup yüz ölçümü 6.551 hektardır. Eğirdir Gölü'nün güneye devamı olan Kovada Gölü, aradaki dar bölgenin alüvyonlarla dolması sonucu ayrı bir göl halini almıştır (URL 24). Alanda briyofit florasına yönelik bir çalışma yürütülmektedir.

\subsection{Köprülü Kanyon Milli Parkı}

Akdeniz Bölgesi'nin Antalya ili sınırları içindedir. 1973 yılında ilan edilmiş olup yüz ölçümü 35.719 hektardır. Milli parkın kaynak değerini oluşturan Köprü Çayının Bolasan Köyü ile Beş konak arasında meydana getirdiği yarma vadi $14 \mathrm{~km}$. uzunluğu ve 100 m'yi aşan duvar yüksekliği ile 
Türkiye'nin en uzun kanyonlarından biridir (URL 25).

Çetin (1988b) tarafindan yapılan CCinclidotus nyholmiae Köprülü Kanyon Milli Parkında 200 m, su kenarı ağaç kök üzerinden bulunmuş ve Türkiye için yeni bir karayosunu taksonudur. Daha sonra bu türün Cinclidotus pachyloma'nın sinonimi olduğu Erdağ ve Kürschner, (2011) tarafindan ifade edilmiştir. (C)inclidotus bistratosus Köprülü Kanyon Milli Parkından (250 m), 1slak kaya üzerinden Türkiye için tespit edilmiş endemik bir karayosunu türüdür (Kürschner and Nestle, 2000). $\boldsymbol{\Delta}$ Fontinalis antipyretica var. gracilis Köprülü Kanyon Milli Parkından (250 m), 1slak kaya üzerinden; Türkiye karayosunu florası için yeni bir karayosunu kaydıdır (Çetin, 1989a).

Karayosunu vejetasyonu ile ilgili 1987-1988 yıllarında içerisinde Çetin (1989b) tarafından Köprülü Kanyon Milli Parkı'nın da içinde bulunduğu Antalya ve çevresinde yaptığı araştırmada 16 familya ve 44 cinse ait, 90 takson kaydedilmiştir. $\mathrm{Bu}$ taksonlar içerisinde 55 takson C12 karesi için yeni kayıttır.

Kırmacı ve Özçelik (2010) tarafindan gerçekleştirilen çalışma sonucunda; 19 familya, 61 cinse ait, 144 karayosunu takson tespit edilmiştir. Bunlardan; 47 karayosunu taksonu C12 karesi için yeni kayıttır.

\subsection{Kuş Cenneti Milli Parkı}

Marmara Bölgesi'nin Balıkesir ili sınırları içindedir. 1959 yılında ilan edilmiş olup yüz ölçümü 17.058 hektardır. Orman rejiminde olmadığı için önce Bakanlar Kurulu Kararı ile orman rejimine alınmış, bilahare milli park statüsü verilmiştir (URL 26).

Ören ve ark., (2007) tarafindan yapılan çalışma sonucunda; 40 familya ve 77 cinse ait 134 briyofit taksonu kaydedilmiş olup bunlardan; 22 karayosunu ve 1 ciğerotu taksonu A1 karesi için yeni kayıttır. Ayrica Weissia levieri (Limpr.) Kindb. ve $\mathbf{\square}$ Fontinalis antipyretica Hedw. subsp. gracilis (Limpr.) Kindb. karayosunu taksonlarının Türkiye'den ikinci kez kaydı verilmiştir.

\subsection{Küre Dağları Milli Parkı}

Batı Karadeniz Bölgesi'nin Kastamonu ve Bartın illeri sınırları içinde yer almaktadır. Milli parkın kaynak değerlerini Valla Kanyonu, Ilgarini Mağarası gibi jeolojik oluşumlar, Ilıca Şelalesi gibi doğal güzellikler, zengin bir flora ve fauna ile otantik, folklorik kültür zenginlikleri oluşturmaktadır (URL 27).

Ören ve ark., (2010) tarafindan yapılan çalışma sonucunda $1056 \mathrm{~m}$, kaya üzerinden toplanan
АAnamodon longifolius'un Türkiye'den ilk defa kaydı verilmiştir.

Ören ve ark., (2012) tarafindan yapılan "The Bryophyte Flora of the Western Part of the Küre Mountains (Bartın, Kastamonu) Turkey" adlı çalışma sonucunda; Toplam 1545 briyofit örneği toplanmış olup bunlardan 60 familya ve 146 cinse ait 272 takson kaydedilmiştir. Bunların; 53 takson ciğerotu ve 2 takson boynuzotu ve 217 takson da karayosunudur. $\mathrm{Bu}$ bulgular sonucunda; 38 taksonun A2 karesi için yeni kayıt ve 4 taksonun da Türkiye için ikinci kez kaydedildiği bildirilmiştir. Bu taksonlar; -Leiocolea badensis, -Cephaloziella rubella, -Diphyscium foliosum ve -Brachythecium tommasinii dir. Ayrica, bu çalışma ile $\boldsymbol{\Delta}$ Seligeria trifaria ve A Pseudotaxiphyllum elegans Türkiye'den ilk defa kaydedilmiş olup Milli Park sınırları dışından kaydı verilmiştir. Henderson (1961) kareleme sistemine göre 9 ciğerotu ve 33 karayosunu taksonu A2 karesi için yeni kayıttır.

Keçeli (2004) tarafindan yapılmış olan "Batı Karadeniz Bölgesi (Bolu, Zonguldak, Bartın, Kastamonu) Ciğerotları (Hepaticae) Florası" adlı doktora çalışması sonucunda; 1128 adet ciğerotu örneği teşhis edilerek Marchantiopsida (Hepaticae) sinıfindan 25 familyaya ait 34 cins ve bu cinslere ait 54 takson; Anthocerotopsida (Anthocerotae) sinıfindan da 1 familyaya ait 1 cins ve bu cinse ait 1 tür olmak üzere toplam 55 ciğerotu taksonu tespit edilmiştir. Bunlardan 18 takson Milli Park sınırlarından toplanmıştır. $\mathrm{Bu}$ türlerden; $\Delta$ Cephaloziella dentata Türkiye Briyofit florası için yeni kayıtır. Buna ek olarak; aScapania aspera'nın Türkiye'nin ciğerotu florası için ikinci kez kaydedildiği görülmüştür.

\subsection{Marmaris Milli Parkı}

Milli Park Akdeniz ve Ege bölgeleri arasındasındaki geçiş bölgesinde olup, Muğla ili sınırları içinde yer almaktadır. 1996 yılında ilan edilmiş olup yüz ölçümü 29.206 hektardır (URL 28). Alanda briyofit florası ile ilgili herhangi bir çalışma yapılmamıştır.

\subsection{Munzur Vadisi Milli Parkı}

Doğu Anadolu Bölgesi'nin Tunceli ili sınırları içinde yer almaktadır. 1971 yılında ilan edilmiş olup yüz ölçümü 42674 hektardır. Munzur Dağlarında, Ovacık ilçesi yakınlarından büyük gözeler halinde doğan Munzur Suyu, Fırat Nehrine karışmaktadır. (URL-29). Alanda briyofit florası ile alakalı herhangi bir çalışma yapılmamıştır.

\subsection{Nemrut Dağı Milli Parkı}

Doğu Anadolu Bölgesi’nin Adıyaman ili sınırları içindedir. 1988 yılında ilan edilmiş olup yüz ölçümü 13.827 hektardır. Milli parkın kaynak 
değeri, eski çağlarda "Kommagene" olarak bilinen arkeolojik kalıntılardır. Antiochos tümülüsü ve buradaki dev heykeller, Eskikale, Yenikale, Karakuş Tepe ve Cendere Köprüsü milli park içinde kalan kültürel değerlerdir (URL 30). Alanda briyofit florasına yönelik herhangi bir çalışma yapılmamıştır.

\subsection{Nene Hatun Tarihi Milli Parkı}

Doğu Anadolu Bölgesi'nin Erzurum ili şehir merkezinde yer alan Milli Park, tarihimize 93 Harbi olarak geçen 1877-1878 Osmanl1-Rus savaşında, şehrin korunmasında etkin rol üstlenen Mecidiye ve Aziziye tabyaları, Rusların kente daha fazla ilerlemesini engellemiştir. Erzurum'u ele geçirmek isteyen Ruslar Ermenilerin de yardımıyla Aziziye Tabyalarına saldırıp, nöbetçileri şehit ederler. Bu haber üzerine Erzurum halkı o zaman henüz 20 yaşında olan Nene Hatun'un önderliğinde kadın-erkek ellerine ne geçirdiyseler Aziziye Tabyasına koşarak büyük bir mücadele sonucunda tabyaları geri alırlar (URL 31). Alanda briyofit florasına yönelik herhangi bir çalışma yapılmamıştır.

\subsection{Saklıkent Milli Parkı}

Akdeniz Bölgesi'nin Antalya ve Muğla illeri sınırları içinde yer almaktadır. Milli parkın kaynak değerini Saklıkent Kanyonu oluşturmaktadır. Eşen Çayının bir kolu üzerindeki kanyon jeomorfolojik olarak ilginç özellikler sergilemektedir (URL 32). Alanda briyofit florasına ile ilgili herhangi bir çalışma yapılmamıştır.

\subsection{Sarıkamış Allahuekber Dağları Milli Parkları}

Doğu Anadolu Bölgesi'nin Kars ve Erzurum illeri sınırları içinde yer almaktadır. 2004 yılında ilan edilmiş olup yüz ölçümü 22.519 hektardır. Doksan bin askerimizin donarak şehit olduğu 1914 yılına ait anılar Milli Parkın tarihi özelliğini teşkil etmektedir (URL 33). Alanda briyofit florası ile ilgili herhangi bir çalışma yapılmamıştır.

\subsection{Soğuksu Milli Parkı}

İç Anadolu Bölgesi’nin Ankara ili sınırları içindedir. 1959 yılında ilan edilmiş olup yüz ölçümü 1.050 hektar iken 1997 yılında yapılan sınır değişikliği ile Milli parkın yüz ölçümü 1.187 hektara ulaşmıştır (URL 34).

Uyar ve Çetin (2001) tarafından yapılan çalışma sonucunda; 20 familya ve 42 cinse ait 116 karayosunu taksonu tespit edilmiş olup bunlardan; 32 takson Henderson (1961) tarafindan düzenlenen kareleme sistemine göre A2 karesi için yeni kayittır.

$\Delta$ Bryum curvatum $(1600 \mathrm{~m})$, 1slak toprak üzerinden alınmış, $\mathbf{\Delta}$ Brachythecium albicans var. dumetorum (1700 m), toprak üzerinden, A Brachythecium velutinum var. validum $1400 \mathrm{~m}$, toprak üzerinden, $\mathbf{\Delta}$ Fontinalis antipyretica var. gigantea $1350 \mathrm{~m}$, taş üzerinden, $\boldsymbol{\Delta}$ Grimmia trichophylla var. robusta $1450 \mathrm{~m}$, kaya üzerinden, ALescuraea radicosa $1700 \mathrm{~m}$, Juniperus communis dal üzerinden ve $\mathbf{\Delta}$ Lescuraea radicosa var. denudata $1675 \mathrm{~m}$, sslak kaya üzerinden alınmış ve Türkiye için ilk defa kaydedilen taksonlardır.

Alanda, Doğan (2007) tarafindan "AnkaraKızılcahamam Soğuksu Milli Parkı Ciğerotları Florası" adlı yüksek lisans tezi gerçekleştirilmiştir. Araştırma sonucunda 25 ciğerotu örneği toplanmış, bunun sonucunda; 4 familya ve 4 cinse ait 4 takson tespit edilmiştir.

\subsection{Spil Dağı Milli Parkı}

Ege Bölgesi'nin Manisa ili sınırları içindedir. 1966 yılında ilan edilmiş olup yüz ölçümü 6.867 hektardır. Karstik yapıda olan Spil Dağı kanyonlara, mağaralara, dolinlere sahiptir (URL 35). Alanda briyofit florasina ait herhangi bir çalışma bulunmamaktadır.

\subsection{Sultan Sazlığı Milli Parkı}

İç Anadolu Bölgesi'nin Kayseri ili, Yeşilhisar, Develi ve Yahyalı ilçeleri arasında, ayrıca üç önemli turizm merkezinin ortasında yer almaktadır. Daha önce tabiatı koruma alanı iken 2006 yılında milli parka dönüştürülmüş olup yüzölçümü 24.357 hektardır (URL 36). Alanda briyofit florasına ait herhangi bir çalışma bulunmamaktadır.

\subsection{Tek Tek Dağları Milli Parkı}

Güneydoğu Anadolu Bölgesinin Şanlıurfa ilinin güneybatısında bulunan Tek tek Dağları üzerinde 19.335 ha.'lık bir alanı kapsamaktadır. Şuayip Şehri Harabeleri, Soğmatar Harabeleri, Senem Mağarası alandaki önemli arkeolojik kalıntılardır. Halk arasındaki bir inanca göre, Şuayip peygamber Şuayip Şehrinde yaşamıştır ve kent adını bu peygamberden almıştır. Kalıntılar arasındaki bir mağara Şuayip peygamberin makamı olarak ziyaret edilir (URL 37). Alanda briyofit florasına ait herhangi bir çalışma bulunmamaktadır.

\subsection{Güllük Dağı - Termessos Milli Parkı}

Akdeniz Bölgesi'nin Antalya ili sınırları içindedir. 1970 yılında ilan edilmiş olup yüzölçümü 6.700 hektardır. Antalya'nın traverten düzlüklerinden yükselen Güllük Dağı'nda Anadolu'nun yerli halklarından olan Salimlerin kurduğu Termesos şehri kalıntıları yer almaktadır. Antik kent çevresinde tepeler, vadiler kanyonlar yer almakta olup, bunlardan Mecene Boğazı adıyla bilineni 600 m. derinliğe ulaşmaktadır (URL 38). 
İçerisinde Güllük Dağı (Termesos) Milli Parkı'nın da bulunduğu Çetin (1989) tarafindan Antalya ve çevresinde yapılan karayosunu florası ile ilgili çalışma sonucunda; 16 familya ve 44 cinse ait, 90 takson kaydedilmiştir. Bunlardan 55 takson $\mathrm{C} 12$ karesi için yeni kayıttır (Çetin, 1989).

\subsection{Troya Tarihi Milli Parkı}

Ege Bölgesi'nin Çanakkale ili sınırları içinde yer almaktadır. 1996 yılında ilan edilmiş olup yüz ölçümü 13.350 hektardır. Milli parkın kaynak değerlerini Troya'lılar ile Aka'ların on yıl süren savaşlarındaki kahraman askerlerin efsanevi öyküleri ile büyük ozan Homeros'un epik eserleri İliada ve Odysseia ile ölümsüzleşen Troya Kenti ve ünlü "Tahta at" oluşturmaktadır (URL-39). Alanda briyofit florasına ait herhengi bir çalışma yapılmamıştır.

\subsection{Uludağ Milli Parkı}

Marmara Bölgesi'nin Bursa ili sınırları içindedir. 1961 yılında ilan edilmiş olup yüz ölçümü 13.024 hektardır. Yüksekliği $2543 \mathrm{~m}$. olan Uludağ, bölgenin en yüksek noktasını oluşturmaktadır. Bursa ovasından yukarı doğru çıkıldığında, bitki kuşaklarının hepsinin botanik bilimindeki tanımlamalara uygun şekilde yer alması Uludağ'a uluslararası alanda ün kazandırmıştır (URL 40).

Çetin (1988c) tarafından yapılan çalışma onucunda; 20 familya ve 41 cinse ait 85 karayosunu takson saptanmıştır. Bunlardan; $\Delta$ Polytrichum commune var. pergoniale ve $\boldsymbol{\Delta}$ Hygrohypnum duriusculum Türkiye karayosunu florası için yeni kayıttır. Tespit edilen taksonlardan 28 tanesi Henderson (1961) kareleme sistemine göre A1 karesi için yenidir (Çetin,1988).

Çetin (1989) tarafından yapılan "Uludağ (Bursa) Milli Parkı'nın Ciğerotları (Hepaticae)" adlı çalışma sonucunda; 15 familyaya ait 17 cins ve 23 ciğgerotu taksonu kaydedilmiştir. Bu taksonlardan; -Marsupella funckii, -Jungermannia hyalina ve -Calypogeia azurea Türkiye'den ikinci kez rapor edilmiştir. Ayrıca; 4 takson Al karesi için yeni kayıttır.

\subsection{Yedigöller Milli Parkı}

Bolu ilinin kuzeyi ve Zonguldak ilinin güneyinde bulunan Yedigöller Milli Parkı 29.04.1965 yılında 6831 sayll Orman Kanununun 25. Maddesi gereği, 1.623 ha'lık orman alanı Milli Park olarak ilan edilmiştir (URL 41).

Çetin ve Yurdakulol (1988) tarafindan yapılan çalışma sonucunda 325 bitki örneği toplandığı ve bunlardan 22 familya ve 54 cinse ait 88 karayosunu taksonu tespit edilmiştir $\mathrm{Bu}$ taksonlardan; $\mathbf{\Delta}$ Fissidens monguillonii (Çetin, 1983) ve $\Delta$ Plagiothecium cavifolium (Çetin
1989), Türkiye briyofit florası için yeni kaydedilen karayosunu taksonlarıdır. Ayrica, 12 takson Henderson (1961) kareleme sistemine göre A2 karesi için yenidir.

Keçeli (2004) tarafindan yapılan "Batı Karadeniz Bölgesi (Bolu-Zonguldak-Bartın-Kastamonu) Ciğerotları (Hepaticae) Florası" adlı doktora çalışması sonucunda Milli park sınırları içerisinde giren 2 familya ve 2 cinse ait 2 takson kaydedilmiştir.

Şimşek ve Çetin (2012) tarafından yapılan "Yedigöller Milli Parkı (Bolu) Ciğerotları (Marchantiophyta) Florasına Katkılar" adlı çalışma sonucunda; 47 ciğerotu örneği toplandığı ve bu örneklerin teşhis sonucunda 12 familya ve 16 ciğerotu taksonu tespit edilmiştir. Bu taksonlardan 1 tanesi Henderson (1961) kareleme sistemine göre Türkiye A2 karesi için yeni kayıttır.

\subsection{Yozgat Çamlığı Milli Parkı}

İç Anadolu Bölgesi'nin Yozgat ili sınırları içindedir. 1958 yılında ilan edilen Türkiye'nin ilk milli parkı olup yüz ölçümü 267 hektardır. Bir zamanlar İç Anadolu'nun büyük bir kısmını kaplayan orman örtüsünden günümüze kadar ulaşan nadir örneklerden biridir (URL 42). Alanda briyofit florasına ait bir çalışma yapılmamıştır.

\subsection{Yumurtalık Lagünü Milli Parkı}

Akdeniz Bölgesi'nin Adana ili, Yumurtalık ilçesi sınırları içerisinde yer alan lagün ve çevresi, 2008 yılında 16.430 ha. olarak Milli Park ilan edilmiştir. Seyhan-Ceyhan deltası göl lagünleri, kıyı kumulları, barındırdığı bitki ve hayvan türleri ile kompleks bir yap1 oluşturmaktadır. Ülkemizde halep çamı (Pinus halepensis)'nin nadir bir yayılış alanı olmasının yanında nesli tehlikeye düşmüş su kuşlarının yaşama ortamıdır. Akyatan ve Ağyatan gölleri barındırdığı kuş türleri açısından Türkiye'deki “A sınıfı" niteliğindeki 19 sulak alandan 2.sini oluşturmaktadır. Ayrıca nesli tehlikeye düşmüş 2 tür deniz kaplumbağasının Caretta caretta ve özellikle Chelonia mydas'ın Akdeniz'de varlığını sürdürebilmesi açısından bu alanlar oldukça önemlidir. Saha, Türkiye'nin Akdeniz kıyılarında yer alan 17 deniz kaplumbağası yuvalama alanlarından birisidir. Özellikle Akdeniz'de yok olma tehlikesi içinde bulunan Chelonia mydas türü kaplumbağa için son sığınma alanlarıdır (URL 43). Alanda briyofit florasına ait herhangi bir çalışma yapılmamıştır.

\subsection{Sakarya Meydan Muharebesi Tarihi Milli Parkı}

İç Anadolu Bölgesi'nin Ankara ili, Polatlı ve Haymana ilçeleri sınırlarında 75 km.'lik bir cepheyi kapsamaktadır. Toplam 13.850 ha. alanı kapsamakta ve 14 parçadan oluşmaktadır. Kaynak 
değerleri Anıtlar, Şehitlikler, Siperler, Lojistik Üstlerdir (URL 44). Alanda briyofit florasına ait herhangi bir çalışma yapılmamıştır.

\subsection{Kop Müdafaası Tarihi Milli Parkı}

Doğu Anadolu Bölgesi'nin Bayburt ili merkez ilçe ve Erzurum Așkale ilçelerinin sınırlarında kalan alan 31.10.2016 tarihinde 6.335 ha alan Milli Park olarak ilan edilmiştir. Bayburt-Kop Savunması; Birinci Dünya Savaşında, Doğu Cephesinde Rus ordusunun durdurulmasında fevkalade önemli bir yeri olan; yalnız doğu cephesinin değil savaşın ve geleceğimizin seyrini değiştiren büyük bir mücadeledir. Şark Cephesinde savaşan 3. Ordu harekatının bilhassa ağırlık merkezini 3. Mıntıka teşkil eder. 3. Mıntıkayı kapsayan Bayburt ve çevresindeki (Kop, Bahtlı Tepe, Ziyarettepe, Çoruh ve Masat Dereleri arasındaki Kalederesi Tepe, Kaçkar, Kırklar Tepe, Soğanlı, Yamalı, Kemer ve Zigana Dağları) savunma savaşlarını V. Kolordu Komutanı olarak M.Fevzi Çakmak 20 Mart-15 Temmuz 1916 tarihleri arasında, tam dört ay süre ile Bayburt'tan idare etmiştir. Birinci Dünya Savaşında Doğu Cephesinin 3. Mıntıkasını teşkil eden alanda top yolları ve savaş mevzileri iklim etmenleri dışında hiç bozulmadan günümüze kadar gelmiştir. Sahada savaşta kullanılmış Osmanlı ve Rus savaş malzemeleri bulunmuştur. Ayrica muhtelif yerlerde mezar yerleri tespit edilmiştir. Saha içinde tarihi sit alanı da bulunmaktadır (URL-45). Alanda briyofit florasına ait herhengi bir çalışma yapılmamıştır.

\section{Tartışma ve Sonuç}

Milli Parklar, sahip oldukları kaynak değerleri ile dünyanın birçok ülkesinde, başta Ecoturizm olmak üzere farklı amaç ve etkinlikler için kullanılmaktadırlar. Söz konusu koruma alanları, turistik çekim gücü kaynakları ile uzun bir süre genellikle turizm amaçlı kullanılsalar da günümüzde çeşitli bilimsel faaliyetler, eğitim alanları ve kaynak değerlerin korunması olarak da değerlendirilmektedirler (Zaman ve Coşkun, 2012).

"Korunan alanların ülke yüzölçümüne oranı" ülkelerin doğal ve kültürel değerlerine karşı bakış açılarını ortaya koyması yönüyle önemli bir ölçüttür. Türkiye, farklı yasal mevzuatlar ve bunların doğrultusunda oluşturulan farklı statüde koruma alanlarına sahiptir (Kaplan, 2003). Bunların ülke yüzölçümüne oranı 2010 y1lı itibariyle \%5,6 dolayındadır (Öztürk, 2010). Buna karşın söz konusu değer İspanya'da \%7,7, Rusya Federasyonu'nda \%8,4, İran'da \%6,7, İtalya'da $\% 12$, Çin Halk Cumhuriyeti'nde \%14, Japonya'da ise $\% 8,5$ gibi ülkemize göre yüksek düzeylerdedir. Ülkemiz için bu oran yetersiz olsa da geçmişten günümüze gösterdiği pozitif artış ümit vermektedir. Örneğin 1960 y1lında 4 olan milli park sayısı, 2012'ye gelindiğinde 39'e ulaşmış, günümüzde bazı güncellemeler ile bu sayı 42'a çıkmıştır. Diğer koruma statüsündeki alanlarda da benzer bir artış söz konusudur.

Tablo 1. Araştırma yapılan Milli Parklarımızın briyofit zenginliği bakımından değerlendirilmesi

\begin{tabular}{|c|c|c|c|c|c|c|c|c|c|c|c|c|c|}
\hline \multirow[b]{2}{*}{ MÍLLİ PARKLAR } & \multicolumn{7}{|c|}{ KARAYOSUNU } & \multicolumn{6}{|c|}{ CİĞEROTU } \\
\hline & 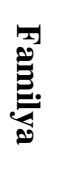 & §ُ & 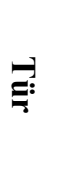 & 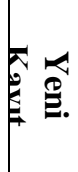 & 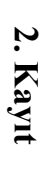 & 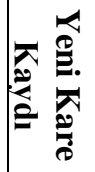 & 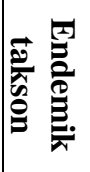 & $\underbrace{2}_{0}$ & ?: & き & 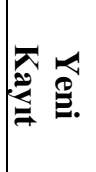 & 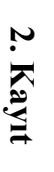 & 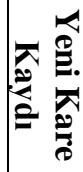 \\
\hline Aladağlar & 29 & 75 & 236 & 1 & 4 & 57 & - & 8 & 9 & 13 & - & 2 & 3 \\
\hline Altındere Vadisi & 15 & 31 & 40 & - & - & 4 & - & 16 & 18 & 33 & - & & 4 \\
\hline $\begin{array}{l}\text { Dilek Yarımadası-Büyük } \\
\text { Menderes Deltası }\end{array}$ & 11 & 22 & 29 & 2 & - & 2 & - & 18 & 18 & 26 & 1 & - & 6 \\
\hline Hatila Vadisi & 16 & 44 & 85 & 2 & & 6 & & - & - & - & - & - & - \\
\hline Honaz Dağı & 24 & 64 & 175 & 2 & - & - & - & 14 & 16 & 21 & - & - & - \\
\hline Ilgaz Dağı & 21 & 56 & 109 & & - & 15 & - & 15 & 19 & 24 & - & - & 2 \\
\hline Kaçkar Dağları & 58 & 125 & 25 & 4 & - & 8 & - & 18 & 32 & 38 & & 1 & 5 \\
\hline Kazdağı & 23 & 63 & 139 & 1 & - & 12 & - & 27 & 32 & 44 & & & 5 \\
\hline Kizıldağ & 29 & 66 & 156 & 2 & 1 & 63 & 2 & - & - & - & - & - & - \\
\hline Köprülü Kanyon & 35 & 105 & 234 & 1 & - & 102 & - & - & - & - & - & - & - \\
\hline Kuş Cenneti & 27 & 63 & 119 & - & - & 24 & - & 13 & 14 & 15 & - & - & 1 \\
\hline Küre Dağları & 33 & 107 & 217 & 2 & 2 & 28 & - & 27 & 39 & 55 & - & 2 & 10 \\
\hline Soğuksu & 20 & 42 & 116 & 7 & - & 32 & - & 4 & 4 & 4 & - & - & - \\
\hline Güllük Dağı - Termessos & 16 & 44 & 90 & - & - & 55 & - & - & - & - & - & - & - \\
\hline Uludağ & 20 & 41 & 85 & 2 & - & 28 & - & 15 & 17 & 23 & - & 3 & 4 \\
\hline Yedigöller & 22 & 54 & 88 & 2 & - & 12 & - & 14 & $?$ & 18 & - & - & 1 \\
\hline TOPLAM & & & & 28 & 7 & 448 & 2 & & & & 1 & 8 & 41 \\
\hline
\end{tabular}


Milli Parklar birçok bitki ve hayvan türlerinin korunması açısından da önemli alanlardır. Fakat bu tip korunan alanlardaki özellikle tohumsuz bitki türleri açısından yeterli envanterinin yapılmaması önemli bir eksikliğimizdir. Bu eksikliği ortaya koymak adına yapılan bu çalışmada şimdiye kadar briyofit florası bakımından yapılmış çalışmaların bir derlemesi ve elde edilen sonuçları Tablo 1 de sunulmuştur.

Tablo 1. inceleyecek olursak 42 adet Milli Parkımızdan sadece 16 tanesi çalışılmıştır. Geriye kalan Milli Parklarımızdan, İğneada Longoz Ormanları Milli Parkı ve Kovada Gölü Milli Parklarında Briyofit Flora çalışmaları Ursavaş ve Keçeli tarafından devam ettirilmektedir. Çalışılan Milli Parklarımızdan Hatila Vadisi, Kızıldağ, Köprülü Kanyon ve Güllük Dağ1- Termessos Milli Parklarında karayosunu flora çalışması yapılmasına karaşın ciğerotlarına yönelik herhangi bir flora çalışması yapılmamıştır. 16 adet Milli Parkımızda toplamda 28 adet karayosunu taksonu ve 1 adet ciğerotu taksonu olmak üzere toplamda 29 adet Türkiye Briyofit florası için yeni kayıt verilmiştir. Tespit edilen taksonlar içerisinde Kızıdağ Milli Parkından 2 adet (Cinclidotus asumaniaea ve $C$. vardaranus) endemik karayosunu taksonunun kaydı verilmektedir.

Görüldüğü üzere Milli Parklarımız bir ülkenin önemli gen kaynaklarını (bitki ve hayvan) içerisinde barındıran alanlardır. $\mathrm{Bu}$ alanların korunması son derece önemlidir fakat Milli Parklarımızı korurken içerisinde neyi koruduğumuzu da bilmemiz gerekmektedir. $\mathrm{Bu}$ yüzden en kısa sürede biz araştırıcıların bu alanlardaki Briyofit zenginliğini ortaya çıkartmamız gerekmektedir.

\section{Kaynaklar}

Abay G. Çetin B. 2003. The moss flora (Musci) of Ilgaz mountain national park", Turkish Journal of Botany. 27: 321-332

Abay G. Uyar G. Çetin B. Keçeli T. 2007. Bucklandiella microcarpa (Hedw.) Bednareck-Ochyra \& Ochyra, (Grimmiaceae, Bryopsida), new to the moss flora of Turkey and South-West Asia, Cryptogamie, Bryologie. 28: 2, 145-148

Abay G. Uyar G. Keçeli T. Çetin B. 2009a. Sphagnum centrale and other remarkable bryophyte record the Kaçkar Mountains (NorthenTurkey). Cryptogamie Bryologie. 339-407

Abay G. Uyar G. Keçeli T. Çetin B. 2009b. New bryofloristic records for the square A4 (Rize, Turkey), Proceedings of IV Balkan Botanical Congress. 134-139 Sofia

Batan N. Özdemir T. 2008. Contributions to the Moss Flora of Artvin Region (Hatilla valley
National Park-Turkey). Pakistan Journal of Biological Sciences. 11:13, 1676-1682

Baydar S. Özdemir T. 1996. Altındere Vadisi Milli Park1 Karayosunları (Musci), Turkish Journal of Botany. 20: 53-57

Çetin B. 1988a. Dilek Yarımadası Milli Park1 Karayosunları (Musci): (I). Doğa Türk Botanik Dergisi. 12:3, 207-214

Çetin B. 1988b. Cinclidotus nyholmiae, a new species from Köprülü Canyon National Park (Antalya) in Turkey. Journal of Bryology. 15: 269-273

Çetin B. 1988c. The Moss of the Uludağ National Park (Bursa/Turkey). Turkish Journal of Botany, 23: 187-193.

Çetin B. 1989a. Köprülü Kanyon, Fauna och Flora. 84: 97-105

Çetin B. 1989b. Antalya Çevresi (Köprülü Kanyon ve Güllük Dağı (Termessos) Milli Parkları ve Kurşunlu Şelalesi) Karayosunları (Musci). Doğa Türk Botanik Dergisi. 13:3, 456-469

Çetin B. 1998. The Liverworts (Hepaticae) of Uludag National Park (Bursa). Turkish Journal of Botany. 23: 277-280

Çetin B. ve Yurdakulol E. 1988. Yedigöller Milli Parkı'nın Karayosunu Florası", Doğa Türk Botanik Dergisi. 12:2 128-145

Doğan H. 2007. Ankara-Kızılcahamam Soğuksu Milli Parkı Ciğerotları (Hepaticae) Florası. Yüksek lisans tezi, Ankara Üniversitesi, Ankara. s 36

Erdağ A. Kürschner H. 2011. The Cinclidotus P. Beauv. / Dialytrichia (Schimp.) Limpr. Complex (Bryopsida, Pottiaceae) in Turkey. Botanica Serbica. 35:1 13-29.

Erdağ A. Yayıntaş A. 1996. A Contribution to the Moss Flora of Western Turkey, Moss Flora of the Kaz Mountain (Balıkesir Turkey), 117-125

Ezer T. Kara R. Seyli T. and Ertek A. 2015. The Bryophyte Flora of Aladağlar National Park (Turkey). Folia Cryptog. Estonica, Fasc. 52: 7-20

Gökler İ. 1998. Liverworts (Marchantiopsida) of the Altındere Valley National Park. Turk. J. of Botany. 22: 409-412

Gökler İ. Özenoğlu H. 1999. Kazdağı Millî Park1 ve Çevresi Ciğer Otlarının Taksonomisi ve Ekolojisi. Çevkor Çevre ve Koruma Dergisi. 8:30, 22-26.

Kaplan, S. 2003. Doğa Koruma Çalışmaları ve Yasalarımız. Kamu Yönetimi Dünyası Dergisi. 4:16, 29-33.

Keçeli T. 2004. Batı Karadeniz Bölgesi (BoluZonguldak-Bartın-Kastamonu) Ciğerotları (Hepaticae) Florası. Doktora tezi. 206 s., Ankara Üniversitesi Fen Bilimleri Enstitüsü, Ankara. 
Keçeli T. 2015. Ayazma Tabiat Parkı (Çanakkale), Kaz Dağları Milli Parkı (Balıkesir) Ciğerotu Florasına Katkılar, XII. Ulusal Ekoloji Ve Çevre Kongresi, Muğla.

Kırmac1 M. 2009. Schistidium dupretii (Thér) W.A. Weber" New national and regional bryophyte records, 22, Journal of Bryology. 31: 201-210, (p. 206).

Kırmacı M. Özçelik H. 2010. Köprülü Kanyon Milli Parkı (Antalya) Karayosunu Florasına Katkıklar. Süleyman Demirel Üniversitesi Orman Fakültesi Dergisi. 2: 59-73

Kırmacı M. Erdağ A. 2009. The Bryophyte Flora of Honaz Mountain (Denizli/Turkey). International journal of Botany. 5:3, 226235

Kürschner, H., Nestle, R.L. 2000. Cinclidotus bistratosus (Cinclidotaceae, Musci), a new species to the hygrophytic moss flora of Turkey, Nova Hedwigia, 70:(3-4), 471-478.

OGM, 2017. Milli Parklar Genel Müdürlüğü http://www.milliparklar.gov.tr/AnaSayfa/M illiParklarDairesi.aspx?sflang=tr. (Erişim tarihi: 10.04.2017)

Ören M. Uyar G. Keçeli T. 2012 The bryophyte flora of the western part of the Küre Mountains (Bartın, Kastamonu), Turkey. p 538-557.

Ören M. Uyar G. Keçeli T. 2007. The Bryophyte Flora of Erdek, Bandirma, Manyas, Districts (Balıkesir, Turkey). p. 1-14

Ören M. Uyar G. Keçeli T. 2010. Anomodon longifolius (Anomodontaceae, Bryopsida) new to the bryophyte flora of Turkey. Turkey Journal of Botany. 34: 141-145

Özdemir T. Koz B. Batan N. 2008. Grimmia ramondii (Grimmiaceae, Bryopsida) for the Second Time record in Turkey and Southwestern Asia. International Journal of Botany, 4:3, 347-348.

Özenoğlu H. Gökler İ. 2002. Dilek Yarımadası Milli Parkı Ciğerotları (Marchantiopsida). Turk J Bot. 26: 297-301

Öztürk, O. 2010. Türkiye Korunan Alanlar Sistemi. Korunan Alanlar İklim Çalıştayı, 15-16 Şubat 2010, Ankara.

Şahin Özdemir. 2008. Epiphytic Algae on Mosses in the Altındere Valley National Park (Maçka-Trabzon/Turkey) p. 2278-2281

Şimşek Ö. Çetin B. Canlı K. 2011. Contributions to the Liverwort (Marchantiophyta) Flora of Ilgaz Mountains (Turkey). Biological Diversity and Conservation 4/1: 7-10

Şimşek Ö. Çetin B. 2012. Yedigöller Milli Parkı (Bolu) Ciğerotları (Marchantiophyta) Florasına Katkılar. 21. Ulusal Biyoloji Kongresi, İzmir. s 580-581.

URL1. Milli Parklar Genel Müdürlüğü. İnternet sitesi. http://www.milliparklar.gov.tr/mp/agridagi/ index.htm [Erişim Tarihi: 25.07.2014].

URL2. Milli Parklar Genel Müdürlüğü. Web sitesi.

http://www.milliparklar.gov.tr/mp/aladaglar /index.htm [Erişim Tarihi: 25.07.2014].

URL3. Milli Parklar Genel Müdürlüğü. Web sitesi. http://www.milliparklar.gov.tr/mp/altinbesi kmagarasi/index.htm [Erişim Tarihi: 26.07.2014].

URL4. Milli Parklar Genel Müdürlüğü. Web sitesi. http://www.milliparklar.gov.tr/mp/altinbesi kmagarasi/sayfa1.htm [Erişim Tarihi: 26.07.2014].

URL5. Milli Parklar Genel Müdürlüğü. Web sitesi. http://www.milliparklar.gov.tr/mp/altindere vadisi/index.htm [Erişim Tarihi: 26.07.2014].

URL6. Milli Parklar Genel Müdürlüğü. Web sitesi. http://www.milliparklar.gov.tr/mp/baskomu tantarihi/index.htm [Erişim Tarihi: 27.07.2014].

URL7. Milli Parklar Genel Müdürlüğü. Web sitesi. http://www.milliparklar.gov.tr/mp/beydagla ri/index.htm [Erişim Tarihi: 03.08.2014].

URL8. Milli Parklar Genel Müdürlüğü. Web sitesi. http://www.milliparklar.gov.tr/mp/beysehir golu/sayfa0.htm [Erişim Tarihi: 03.08.2014].

URL9. Milli Parklar Genel Müdürlüğü. Web sitesi. http://www.milliparklar.gov.tr/mp/bogazko yalacahoyuk/index.htm [Erişim Tarihi: 03.08.2014].

URL10. Milli Parklar Genel Müdürlüğü. Web sitesi.

http://www.milliparklar.gov.tr/mp/dilekyari madasi/index.htm [Erişim Tarihi: 03.08.2014].

URL11. Milli Parklar Genel Müdürlüğü. Web sitesi.

http://www.milliparklar.gov.tr/mp/galagolu/ index.htm [Erişim Tarihi: 03.08.2014].

URL12. Milli Parklar Genel Müdürlüğü. Web sitesi.

http://www.milliparklar.gov.tr/mp/goremeta rihi/index.htm [Erişim Tarihi: 03.08.2014].

URL13. Milli Parklar Genel Müdürlüğü. Web sitesi.

http://www.milliparklar.gov.tr/mp/goremeta rihi/sayfa1.htm [Erişim Tarihi: 03.08.2014].

URL14. Milli Parklar Genel Müdürlüğü. Web sitesi.

http://www.milliparklar.gov.tr/mp/hatilavad isi/index.htm [Erişim Tarihi: 23.08.2014].

URL15. Milli Parklar Genel Müdürlüğü. Web sitesi. http://www.milliparklar.gov.tr/mp/honazda gi/index.htm [Erişim Tarihi: 23.08.2014].

URL16. Milli Parklar Genel Müdürlüğü. Web sitesi. 
http://www.milliparklar.gov.tr/mp/igneadal ongozormanlari/index.htm [Erişim Tarihi: 23.08.2014].

URL17. Milli Parklar Genel Müdürlüğü. Web sitesi.

http://www.milliparklar.gov.tr/mp/ilgazdagi /index.htm [Erişim Tarihi: 01.09.2014].

URL18. Milli Parklar Genel Müdürlüğü. Web sitesi.

http://www.milliparklar.gov.tr/mp/ilgazdagi /sayfa1.htm [Erişim Tarihi: 01.09.2014].

URL19. Milli Parklar Genel Müdürlüğü. Web sitesi.

http://www.milliparklar.gov.tr/mp/kackarda glari/index.htm [Erişim Tarihi: 01.09.2014].

URL20. Milli Parklar Genel Müdürlüğü. Web sitesi.

http://www.milliparklar.gov.tr/mp/karagols

ahara/index.htm [Erişim Tarihi: 01.09.2014].

URL21. Milli Parklar Genel Müdürlüğü. Web sitesi.

http://www.milliparklar.gov.tr/mp/karatepe aslantas/index.htm [Erişim Tarihi: 01.09.2014].

URL22. Milli Parklar Genel Müdürlüğü. Web sitesi.

http://www.milliparklar.gov.tr/mp/kazdagi/i ndex.htm [Erişim Tarihi: 21.09.2014].

URL23. Milli Parklar Genel Müdürlüğü. Web sitesi.

http://www.milliparklar.gov.tr/mp/kizildag/ index.htm [Erişim Tarihi: 21.09.2014].

URL24. Milli Parklar Genel Müdürlüğü. Web sitesi.

http://www.milliparklar.gov.tr/mp/kovadag olu/index.htm [Erişim Tarihi: 21.09.2014].

URL25. Milli Parklar Genel Müdürlüğü. Web sitesi.

http://www.milliparklar.gov.tr/mp/kopruluk anyon/index.htm [Erişim Tarihi: 03.10.2014].

URL26. Milli Parklar Genel Müdürlüğü. Web sitesi.

http://www.milliparklar.gov.tr/mp/kuscenne ti/index.htm [Erişim Tarihi: 03.10.2014].

URL27. Milli Parklar Genel Müdürlüğü. Web sitesi.

http://www.milliparklar.gov.tr/mp/kuredagl ari/index.htm [Erişim Tarihi: 03.10.2014].

URL28. Milli Parklar Genel Müdürlüğü. Web sitesi.

http://www.milliparklar.gov.tr/mp/marmari s/index.htm [Erişim Tarihi: 03.10.2014].

URL29. Milli Parklar Genel Müdürlüğü. Web sitesi.

http://www.milliparklar.gov.tr/mp/munzurv adisi/index.htm [Erişim Tarihi: 03.10.2014].
URL30. Milli Parklar Genel Müdürlüğü. Web sitesi.

http://www.milliparklar.gov.tr/mp/nemrutd agi/index.htm [Erişim Tarihi: 03.10.2014].

URL31. Milli Parklar Genel Müdürlüğü. Web sitesi.

http://www.milliparklar.gov.tr/mp/nenehatu n/index.htm [Erişim Tarihi: 07.10.2014].

URL32. Milli Parklar Genel Müdürlüğü. Web sitesi.

http://www.milliparklar.gov.tr/mp/saklikent /index.htm [Erişim Tarihi: 07.10.2014].

URL33. Milli Parklar Genel Müdürlüğü. Web sitesi.

http://www.milliparklar.gov.tr/mp/sarikami sallahuekberdaglari/index.htm [Erişim Tarihi: 07.10.2014]

URL34. Milli Parklar Genel Müdürlüğü. Web sitesi.

http://www.milliparklar.gov.tr/mp/soguksu/ index.htm [Erişim Tarihi: 07.10.2014].

URL35. Milli Parklar Genel Müdürlüğü. Web sitesi.

http://www.milliparklar.gov.tr/mp/spildagi/i ndex.htm [Erişim Tarihi: 07.10.2014].

URL36. Milli Parklar Genel Müdürlüğü. Web sitesi.

http://www.milliparklar.gov.tr/mp/sultansaz ligi/index.htm [Erişim Tarihi: 27.10.2010].

URL37. Milli Parklar Genel Müdürlüğü. Web sitesi.

http://www.milliparklar.gov.tr/mp/tektekda glari/index.htm [Erişim Tarihi:27.10.2014].

URL38. Milli Parklar Genel Müdürlüğü. Web sitesi.

http://www.milliparklar.gov.tr/mp/termesso s/index.htm [Erişim Tarihi:27.10.2014].

URL39. Milli Parklar Genel Müdürlüğü. Web sitesi.

http://www.milliparklar.gov.tr/mp/troyatari hi/index.htm [Erişim Tarihi:27.10.2014].

URL40. Milli Parklar Genel Müdürlüğü. İnter Web net sitesi. http://www.milliparklar.gov.tr/mp/uludag/i ndex.htm [Erişim Tarihi:27.10.2014].

URL41. Milli Parklar Genel Müdürlüğü. Web sitesi.

http://www.milliparklar.gov.tr/mp/yedigolle r/index.htm [Erişim Tarihi:27.10.2014].

URL42. Milli Parklar Genel Müdürlüğü. Web sitesi.

http://www.milliparklar.gov.tr/mp/yozgatca mligi/index.htm Tarihi:27.10.2014].

[Erişim

URL43. Milli Parklar Genel Müdürlüğü. Web sitesi.

http://www.milliparklar.gov.tr/mp/yumurtal iklagunu/index.htm [Erişim Tarihi: 09.11.2017]. 
URL44. Milli Parklar Genel Müdürlüğü. Web sitesi.

http://bolge9.ormansu.gov.tr/9bolge/AnaSa yfa/falliyetlerimiz/milliparklar/sakaryamey danmp.aspx?sflang=tr [Erişim Tarihi: 09.11.2017].

URL45. Milli Parklar Genel Müdürlüğü. Web sitesi. http://bolge13.ormansu.gov.tr/13bolge/Ana Sayfa/milliparklar/kop.aspx?sflang=tr [Erişim Tarihi: 09.11.2017].

Ursavaş S. Çetin B. 2012. Seligeria donniana (Sm.) Müll. Hal. (Seligeriaceae) a new record to the bryophyte flora of Turkey. Biological Diversity and Conservation. 5:2, 70-72.

Ursavaş S. Çetin B. 2013. Contribution to the Moss Flora of Kizildağ (Isparta) National Park in Turkey. Current Progress in Biological Research, ISBN 978-953-511097-2, InTech.

Ursavaş S. Çetin B. 2014. Cinclidotus asumaniae Ursavaş \& Çetin (Bryopsida, Pottiaceae), sp. nov., a new species to the hygrophytic moss flora of Southern Turkey. Nova Hedwigia, 98:3-4, 467-472.

Uyar G. Abay G. Çetin B. Keçeli, T. 2008. Dicranum flexicaule Brid. (Dicranaceae, Bryopsida), new to the moss flora of southwest Asia", Criptogamie, Bryologie. 29:1, 103-106.

Uyar G. Çetin B. 2001. The Moss of Ankara Kızılcahamam Soğuksu National Park. Turkish Journal of Botany, 25: 261-273

Yayıntaş, T.Ö. 2009. Trachycystis ussuriensis (Maack \& Regel) T.J. Kop. A new moss record from Turkey, Nova Hedwigia, 88:12, 129-132.

Zaman, S. Çoşkun O. 2012. Milli Parklarda Kaynak Değer Kullanımı İçin Bir Öneri: Nene Hatun Tarihi Milli Parkı. Atatürk Üniversitesi Sosyal Bilimler Enstitüsü Dergisi. 16:3, 117-134. 